\title{
A game of tag or a deep and meaningful relationship?
}

\author{
Peter Ward \\ Chief Executive, BDA
}

Several of our political masters have ranged forth on the subject of access to NHS dental services. One unifying thing about all of their observations seems to be that they think this is a good thing (as indeed do we at the BDA). The next is that they want more of it. But what appears to be missing is a clear and consistent definition of what type or level of service to which they want to improve access.

The current NHS arrangements in Scotland are largely similar to those that were in force across the whole of the UK until March 2006. Northern Ireland is in a state of flux and Wales and England are now in the world of locally commissioned services designed by local primary care organisations. In Scotland, the bulk of contractual payments come from items of clinical treatment individually counted and additional funding derived from allowances, some of which are dependent on the practitioner's commitment to the NHS - but there is also a contractual encouragement to maintain a relationship between practitioner and patient. In England and Wales there is no such encouragement to maintain the relationship and the emphasis in the contract currency is on the number of courses of treatment. Northern Ireland is in the process of negotiating terms, but it is likely that there will be a hybrid system there.

What this means is that the National Health Service of Great Britain and Northern Ireland has at least three different underpinning philosophies when it comes to commissioning dental services. Beyond these positions, the greater autonomy enjoyed by the primary care organisations in all corners of the Kingdom means that local interpretation varies and greater contractual freedom means that system design creates yet further variability.

So, when policy formers talk of increasing access to NHS services what do they mean? Which philosophy, local interpretation or system design do they prefer? Is it the case that these different approaches are merely an exercise in local sensitivity, or does this range of variety mean that speaking about access as an holistic entity is spurious? To answer the question, let's look at the type of access that is encouraged at the opposite ends of the spectrum.

\section{DIFFERENCES FROM DUMFRIES TO CARLISLE}

A patient seeking 'access to NHS dental services' in Scotland will meet a practitioner who is contractually encouraged to register the patient as a patient of the practice, seek out and treat all the disease present, and maintain a high level of commitment to the National Health Service. Just across Hadrian's Wall in England, a patient seeking 'access to NHS dental services' will meet a practitioner who has no contractual encouragement to maintain relationships, but in fact, may be under pressure by the PCT to keep space available to see new patients (and so limit the opportunity to permit repeat relationships), is subject to contractual terms which discourage clinical interventions beyond the minimum, is under threat of contractual sanctions if he or she spends too long treating individual patients, and has his or her opportunity to offer private alternatives to treatment limited by regulatory restrictions and financial controls. I suspect that the trip from Dumfries to Carlisle may reveal some very significant differences in the way 'access to NHS dental services' feels.

Last year Professor Steele completed his review and published a very well thought out set of proposals indicating that which 21st Century dental care should be about in England. His basic premise was that by emphasising the prevention of disease, the restoration of health and the repair of damage, an affordable and health-improving service could be delivered. It is unclear why, even though that highly energetic and wellinvested research exercise was being carried out, the Department of Health in England could not wait for its findings before developing a contracting framework that would reinforce the worst excesses of the current arrangements. One must wonder what Professor Steele must think about the fact that at the same time he was methodically putting together a plan to improve the nation's health, the government was indifferently developing a contracting system focused on driving down price and reducing patient/practitioner contact to 'treatment episodes'.

If we are really serious about getting value from the money we all spend as taxpayers we should also have a view about what type of access is really valuable. Designing a system that drives down local unit price may seem clever and it probably feels quite macho. Driving throughput of patient episodes probably makes it easier for accountants to quantify access. But whether these approaches represent sustainable healthcare I leave others to judge and time to tell. For my money (and the tax I contributed in commissioning Steele) a well motivated workforce incentivised to provide care and health improvement is a better investment than an approach that makes it easier for bean-counters. So, as you can see, I think that whilst the long term relationship may be more involved, the results it yields are far more worthwhile than the game of tag.

DOI: $10.1038 /$ sj.bdj.2010.211 